\title{
Beneficial effects of Monascus purpureus NTU 568 -fermented products on cholesterol in vivo and clinical trial: A review
}

\author{
Chien-Li Chen ${ }^{1}$ and Tzu-Ming Pan ${ }^{1,2 *}$ \\ ${ }^{1}$ Research and Development Division, SunWay Biotech Co., Ltd., Taipei, Taiwan \\ ${ }^{2}$ Department of Biochemical Science and Technology, College of Life Science, National Taiwan University, Taipei, Taiwan
}

\begin{abstract}
Red yeast rice (RYR) is prepared by fermenting rice with Monascus. RYR contains the compound monacolin K-the same active ingredient found in prescription cholesterol-lowering medications like lovastatin. Hypercholesterolemia is a dangerous form of cardiovascular disease, for which statins are generally prescribed as the main therapeutic drug. One of the most common complaints of people taking statins is muscle pain as a soreness, tiredness, weakness or induced rhabdomyolysis. The U.S. Food and Drug Administration has issued warnings that memory loss, mental confusion, neuropathy, high blood sugar, and type 2 diabetes are possible side effects. Monascus purpureus NTU 568-fermented product (Ankascin 568-R) contains monascin and ankaflavin as major active compounds, which was different from Monascus species fermented major compound monacolin K. Due to the high levels of Monascus metabolites and other ingredients, minimal amounts of Ankascin 568$\mathrm{R}$ can be completely assimilated into the digestive system. Clinical results have showed statistically significant decreases of $11.9 \%$ and $19.0 \%$ were observed in total cholesterol and low-density lipoprotein cholesterol levels, respectively. This systematic review describes the applications, side effects, and health benefits of monacolin $\mathrm{K}$, monascin, and ankaflavin in Monascus-fermented products based on animal studies and clinical trial. Empirical studies suggest that a potentially useful agent for the regulation of blood lipids and the treatment of coronary artery diseases.
\end{abstract}

\section{Introduction}

In Europe and the USA, more than $51 \%$ of total mortality is caused by cardiovascular diseases (including stroke, hypertension, and coronary heart disease) as a result of high blood cholesterol [1]. Monacolin K, also known as lovastatin, is a cholesterol-lowering compound produced by Monascus, it is the major active component in traditional red yeast rice (RYR) [2]. Statins can lead to myalgia (muscle pain), myopathy, elevated creatinine kinase (myonecrosis), and rhabdomyolysis [3]. The onset of myalgia varies from patient to patient, from a few weeks to years after the initiation of statin therapy [4]. In rhabdomyolysis, the release of intracellular muscle constituents due to muscle injury could lead to renal failure [5]. According to new safety updates, the FDA warned consumers to avoid cholesterol-lowering red mold rice (RMR) supplements promoted on the Internet [6] (RMR, RMRpolicosanol complex, and Cholestrix), which may lead to myopathy and kidney dysfunction. The FDA does not recommend statin/monacolin $\mathrm{K}$ as dietary supplements owing to the risk of serious myopathies and rhabdomyolysis [7-9]. The increasing focus on evidence-based medicine, as well as the lack of studies and regulations to ensure the safety of these products have prompted skepticism among healthcare professionals regarding dietary supplements and herbal products that have otherwise proved to be safe and efficacious $[10,11]$. In this review, we describe a strain with promising health benefits, Ankascin ${ }^{\circ} 568-\mathrm{R}$, and summarize the effects of monascin (MS), ankaflavin (AK), and monacolin $\mathrm{K}(\mathrm{MK})$ based on animal models and a clinical study.

\section{Monascus purpureus NTU 568 isolation and new functional ingredients}

The red yeast strain Monascus purpureus NTU 568 has been isolated and studied for more than 10 years by the research team of Professor
Tzu-Ming Pan (National Taiwan University). A new type of RYR (Ankascin 568-R), a product of fermentation by M. purpureus NTU 568 obtained by SunWay Biotech., Co., Ltd. (Taipei, ROC), contains high levels of two major active compounds, MS and AK. These yellow pigments are naturally produced by Monascus species.

\section{Beneficial effects of monascin (MS) and ankaflavin (AK) in cholesterol management}

We have previously shown that in hyperlipidemic hamsters, Ankascin 568-R has better hypolipidemic and antiatherosclerosis in addition to MK [12]. The yellow pigments MS/AK not only possess hypolipidemic functions reduced the total cholesterol (TC), triglyceride (TG), and low-density lipoprotein cholesterol (LDL-C) levels, with an inhibitory activity by 29.8 (MS)/28.6\% (AK), 63.4 (MS)/58.2\% AK), and 33.9 (MS)/42.3\% (AK), respectively, but also could increase highdensity lipoprotein cholesterol (HDL-C) levels by 16.4 (MS)/20.9\% (AK) $[12,13]$, explaining the better hypolipidemic and HDL-Celevating effects of Ankascin 568-R [13]. Hyperlipidemia refers to increased levels of lipids (fats) in the blood, including TC and TG. It

${ }^{*}$ Correspondence to: Tzu-Ming Pan, Department of Biochemical Science and Technology, College of Life Science, National Taiwan University, No. 1, Sec. 4, Roosevelt Road, Taipei 10617, Taiwan, Tel: +886-2-33664519 (Extn. 10); Fax: +886-2-33663838; E-mail: tmpan@ntu.edu.tw

Key words: ankaflavin, hyperlipidemia, monacolin K, monascin, Monascus purpureus NTU 568, rhabdomyolysis

Received: August 07, 2019; Accepted: August 22, 2019; Published: August 27, 2019 
can significantly increase the risk of cardiovascular disease, including diseases of blood vessels supplying the heart, brain, and limbs. These conditions can lead to chest pain, heart attacks, strokes, and other problems. Therefore, the management of hyperlipidemia requires the control of TC and TG.

\section{Effects and side effects of monascin, ankaflavin, and monacolin $\mathrm{K}$}

We compared the hypolipidemic and anti-atherosclerosis effects of MS, AK, and MK under the same dosages, including analyses of side effects. MS and AK had similar effects to those of MK, i.e., they significantly reduced TC, TG, and LDL-C levels in the serum and plaque accumulation in the aorta. Although the reductions in serum TC and TG by AK and MK were similar, AK had more significant effects on the prevention of fatty liver and lipid plaque accumulation in the aorta than those of MK. More importantly, MS significantly enhanced HDL-C concentrations, while MK had the opposite effect [14]. With respect to side effects, we evaluated whether the interaction between Monascusfermented products and lovastatin contributes to an increased risk of rhabdomyolysis. MK elevated creatinine phosphokinase (CPK) activity, which is highly correlated with rhabdomyolysis development, while this side effect was not observed for MS and AK. Accordingly, MS and AK have the potential to be used as hypolipidemic agents, without increasing the risk of rhabdomyolysis. The administration of Ankascin $568-\mathrm{R}$ alone or in combination with lovastatin did not cause significant rhabdomyolysis, as determined by the levels of CPK. Further, we did not find any study that clearly implicates Ankascin 568-R in liver and kidney toxicity [15].

\section{Safety}

Monascus-fermented products may be contaminated by citrinin, which could damage the kidneys and liver. Citrinin, a toxic secondary metabolite of certain fungi, was first isolated as a pure compound from Penicillium citrinum in 1931 [16]. It is produced by various Penicillium, Aspergillus, and Monascus species [17,18]. It is widely considered a hazardous contaminant of foods and feeds, including grains, fruits, and oil seeds [19]. As citrinin poses a risk to human health, many countries and scientific committees have established maximum levels for food [20]. However, according to Sáncheza et al. [21] in an EFSA report, there are insufficient data to determine the upper limits of daily exposure to citrinin for humans and animals. Animals and humans are exposed to citrinin by the consumption of contaminated food, inhalation, and skin contact [22]. Evaluations of Monascus-fermented products for an experimental period of as long as four months have shown no toxicity [23]. Recent studies have confirmed that Monascusfermented products do not have adverse health effects, and the control of the citrinin concentration in Monascus-fermented products is an important issue [24]. Increasing the concentration of $\mathrm{MK}$ and decreasing the concentration of citrinin have been evaluated by several laboratories [25-27]. Various citrinin concentrations (1, 2, 10, 20, and $200 \mathrm{ppm}$ ) in RMR have been evaluated for safety in animal tests [28]. In a 90-day animal test, the no-observable-adverse-effect level (NOAEL) was $200 \mathrm{ppm}$ citrinin for male Wistar rats. The safe concentration of citrinin in Monascus-fermented products is $2 \mathrm{ppm}$. Owing to the substantial concern regarding citrinin contamination, Japan has issued an advisory limit of $200 \mathrm{ppb}$; the current FDA action level in agricultural products on the market is $20 \mathrm{ppb}$ citrinin, and the European Union has recommended a limit of $100 \mathrm{ppb}$. Recent investigations are focused on conditions for reducing the citrinin concentration in Monascusfermented products during production.

\section{Ankascin 568-R, containing monascin and ankaflavin, can regulate blood lipids and impact heart health (clinical trial)}

The most common causes of heart disease, such as metabolic syndrome, involve several cardiovascular risk factors, such as central obesity, hyperglycemia, hypertension, and hyperlipidemia, which are pathogenically correlated. In a clinical study, 57 qualified subjects were initially enrolled and 17 were withdrawn owing to contraindicated diseases or sensory problems, for a total of 40 subjects assigned to test and placebo groups. The dietary behavior and lifestyle of the subjects did not change during the study and no clinical syndromes or discomfort were recorded. In addition, there were no differences in anthropometric measurements after eight weeks of intervention between the test and placebo groups. TC and LDL-C levels in the treatment group $(500 \mathrm{mg}$ of Ankascin 568 Plus/day, include Ankascin 568-R 110 mg) decreased significantly, by $11.9 \%$ and $19.0 \%$, respectively. In the placebo group, TC and LDL-C levels only changed by $0.1 \%$ and $1.9 \%$, respectively. Compared with levels in the placebo group, Ankascin 568 Plus can indeed reduce TC and LDL-C. The serum TG levels in the treatment and placebo groups at weeks $0,4,8$, and 12 did not differ between the treatment and placebo groups. However, the TG values showed considerable variation among patients in each group. This intragroup variability might explain the lack of statistically significant differences between groups. Furthermore, LDL-C levels and the LDL-C/HDL-C ratio were significantly lower in the Ankascin 568 Plus-treated group than in the placebo group. LDL-C is a key indicator of coronary heart disease. It is an important lipoprotein cholesterol that can be transported to the body cells for use. However, high blood levels of LDL-C result in accumulation in the vessel walls, leading to atherosclerosis. Therefore, high LDL-C is considered a risk factor for vascular obstruction. In contrast, HDL-C is an essential substance for the prevention of atherosclerosis and is widely used to assess the incidence of coronary artery disease; low levels are an important predictor of coronary atherosclerosis. Ankascin 568 Plus regulates blood lipids and reduces cardiovascular disease. The administration of Ankascin 568 Plus had no significant effects on the metabolic or physiological function of the kidneys. These results clearly support the use of Ankascin 568 Plus for substantially reducing the risk of cardiovascular diseases [29].

\section{Conclusions}

Recent studies of RYR products contribute to improved food safety management by consumer protection authorities. Ankascin 568 Plus produced by M. purpureus NTU 568 fermentation is a potentially useful agent for the regulation of blood lipids and the treatment of coronary artery diseases.

\section{References}

1. Benjamin EJ, Blaha MJ, Chiuve SE, Cushman M, Das SR, et al. (2017) Heart disease and stroke statistics - 2017 update: A report from the American Heart Association. Circulation 135: e146-e603. [Crossref]

2. Lin YL, Wang TH, Lee MH, Su NW (2008) Biologically active components and nutraceuticals in the Monascus-fermented rice: a review. Appl Microbiol Biotechnol 77: 965-973. [Crossref]

3. Camerino GM, De Bellis M, Conte E, Liantonio A, Musaraj K, et al. (2016) Statininduced myotoxicity is exacerbated by aging: A biophysical and molecular biology study in rats treated with atorvastatin. Toxicol Appl Pharmacol 306: 36-46. [Crossref]

4. Tobert JA (1988) Efficacy and long-term adverse effect pattern of lovastatin. Am J Cardiol 62: J28-J34. [Crossref]

5. Echaniz-Laguna A, Mohr M, Tranchant C (2010) Neuromuscular symptoms and elevated creatine kinase after statin withdrawal. $N$ Engl J Med 362: 564-565. [Crossref] 
6. FDA (2019) FDA warns consumers to avoid red yeast rice products promoted on internet as treatments for high cholesterol products found to contain unauthorized drug. Available from: http://www.fda.gov/NewsEvents/Newsroom/PressAnnouncements/ ucm108962.htm. Accessed August 08, 2019.

7. Ambapkar SN, Shetty N, Dwivedy A, Malve HO (2016) Statin-induced rhabdomyolysis in patient with renal failure and underlying undiagnosed hypothyroidism. Indian J Crit Care Med 20: 305-307. [Crossref]

8. Hoffman KB, Kraus C, Dimbil M, Golomb BA (2012) A survey of the FDA's AERS database regarding muscle and tendon adverse events linked to the statin drug class. PloS One 7: e42866. [Crossref]

9. Murakami H, Sakaeda T, Kadoyama K, Okuno Y (2013) Gender effects on statinassociated muscular adverse events: an analysis of the FDAAERS database. Pharmacol Pharm 4: 340-346.

10. Law M, Rudnicka AR (2006) Statin safety: a systematic review. Am J Cardiol 97: 52C-60C. [Crossref]

11. Bakri R, Wang J, Wierzbicki AS, Goldsmith D (2003) Cerivastatin monotherapyinduced muscle weakness, rhabdomyolysis and acute renal failure. Int $J$ Cardiol 91: 107-109. [Crossref]

12. Lee CL, Hung HK, Wang JJ, Pan TM (2007) Red mold dioscorea has greater hypolipidemic and antiatherosclerotic effect than traditional red mold rice and unfermented dioscorea in hamsters. J Agric Food Chem 55: 7162-7169. [Crossref]

13. Lee CL, Kung YH, Wu CL, Hsu YW, Pan TM (2010) Monascin and ankaflavin act as novel hypolipidemic and high-density lipoprotein cholesterol-raising agents in red mold dioscorea. J Agric Food Chem 58: 9013-9019. [Crossref]

14. Lee CL, Hung YP, Hsu YW, Pan TM (2013) Monascin and ankaflavin have more antiatherosclerosis effect and less side effect involving increasing creatinine phosphokinase activity than monacolin K under the same dosages. J Agric Food Chem 61: 143-150. [Crossref]

15. Chen CL, Pan TM (2012) Red mold dioscorea: A potentially safe traditional function food for the treatment of hyperlipidemia. Food Chem 134: 1074-1080. [Crossref]

16. Hetherington AC, Raistrick H (1931) Studies in the biochemistry of micro-organism. XI. On the production and chemical constitution of a new yellow colouring matter, citrinin, produced from glucose by Penicillium citrinum Thom. Philos Trans $R$ Soc Lond B 220: 269-297.
17. El-Banna A, Pitt J, Leistner L (1987) Production of mycotoxins by Penicillium species. Syst Appl Microbiol 10: 42-46.

18. Li F, Xu G, Li Y, Chen Y (2003) Study on the production of citrinin by Monascus strains used in food industry. Wei Sheng Yan Jiu 32: 602-605. [Crossref]

19. Bennett JW, Klich M (2003) Mycotoxins. Clin Microbiol Rev 16: 497-516. [Crossref]

20. Aydin Y, Orta Yilmaz B1, Yildizbayrak N1, Korkut A2, Arabul Kursun M, et al. (2019) Evaluation of citrinin-induced toxic effects on mouse Sertoli cells. Drug Chem Toxicol 29: 1-7. [Crossref]

21. Sáncheza PL, de Nijsa M, Spanjerb M, Pietric A, Bertuzzic T, et al. (2017) Generation of occurrence data on citrinin in food. EFSA Supporting Publications 14: 1-47.

22. Richard JL, Payne GA, Desjardins AE, Maragos C, Norred WP, et al. (2003) Mycotoxins: risks in plant, animal and human systems. CAST Task Force Report 139: $1-191$.

23. Li C, Zhu Y, Wang Y (1998) Monascus purpureus fermented rice (red yeast rice): a natural food product that lowers blood cholesterol in animal models of hypercholesterolemia. Nutr Res 18: 71-81.

24. Klimek M, Wang S, Ogunkanmi A (2009) Safety and efficacy of red yeast rice (Monascus purpureus) as an alternative therapy for hyperlipidemia. P T 34: 313-327. [Crossref]

25. Wang JJ, Lee CL, Pan TM (2004) Modified mutation method for screening low citrininproducing strains of Monascus purpureus on rice culture. J Agric Food Chem 52: 6977-6982. [Crossref]

26. Yongsmith B, Kitprechavanich V, Chitradon L, Chaisrisook C, Budda N (2000) Color mutants of Monascus sp. KB9 and their comparative glucoamylases on rice solid culture. J Mol Catal 10: 263-272.

27. Chen F, Hu X (2005) Study on red fermented rice with high concentration of monacolin $\mathrm{K}$ and low concentration of citrinin. Int J Food Microbiol 103: 331-337. [Crossref]

28. Lee CH, Lee CL, Pan TM (2010) A 90-D toxicity study of Monascus-fermented products including high citrinin level. J Sci Food Agric 75: 91-97. [Crossref]

29. Liu SF, Wang YR, Shen YC, Chen CL, Huang CN, et al. (2018) A randomized, doubleblind clinical study of the effects of Ankascin 568 plus on blood lipid regulation. J Food Drug Anal 26: 393-400. [Crossref]

Copyright: (C2019 Chien-Li C. This is an open-access article distributed under the terms of the Creative Commons Attribution License, which permits unrestricted use, distribution, and reproduction in any medium, provided the original author and source are credited. 